\title{
Effects of Topical Honey Dressing in Decubitus Ulcer
}

\author{
S. Khadanga' ${ }^{1}$, D. Dugar ${ }^{2}$, T. Karuna ${ }^{3}$, R. Khetri ${ }^{4}$, H. Tim ${ }^{5}$, S. Ghata ${ }^{6}$, P.K. Thatoi ${ }^{7}$ \\ ${ }^{1}$ Khadanga Sagar, M.D. Assistant Professor, Department of Medicine, AllMS Bhopal, Madhya Pradesh, India, ${ }^{2}$ Dharmendra Dugar, M.S. \\ Assistant Professor, Department of General Surgery, Hi-Tech Medical College and Hospital, Bhubaneswar, Odisha, India, ${ }^{3} T$. Karuna, M.D. \\ Assistant Professor, Department of Microbiology, AlIMS Bhopal, Madhya Pradesh, India, ${ }^{4}$ Ramji Khetri, M.S. Associate professor, Department \\ of General Surgery, Hi-Tech Medical College and Hospital, Bhubaneswar, Odisha, India, ${ }^{5}$ Tim Houghton T, P.G Student. Department of \\ General Surgery, Hi-Tech Medical College and Hospital, Bhubaneswar, Odisha, India, ${ }^{6}$ Swarupjit Ghata, P.G Student. Department of General \\ Surgery, Hi-Tech Medical College and Hospital, Bhubaneswar, Odisha, India, ${ }^{7}$ Pravat Kumar Thatoi, MD. Assistant Professor, Department of \\ Medicine, SCB Medical College, Cuttack, Odisha,India
}

Background: The medicinal properties of honey have been recognized since antiquity. Although used as an adjuvant method for accelerating wound healing from ancient times, honey has been sporadically used in the treatment of wounds. Many researchers have shown that honey exerts antibacterial activity against various organisms, including both Gram-positive and Gram-negative bacteria. Aims and Objectives: This study was done to compare the effectiveness of honey and povidone iodine in wound healing in decubitus ulcers. Materials and Methods: We conducted a hospital based observational, cross sectional study of 40 patients with bed sore. Patients were selected considering the inclusion and exclusion criteria. Twenty patients (Group A) had honey dressing and another 20 patients (Group B) had povidone iodine dressing. We compared the wound healing status and bacteriological profile between day 1 and day 10 in both the groups. Results: The pain score decrement was significant in honey dressing group but the reduction in size of the wound was not significant. The bacteriological profile was more or less similar in both the groups at the start and end of the study. Conclusions: The antibacterial properties of honey, the cost effectiveness, easy availability, reduction in size of wound and more so the significant reduction in pain reveal that honey can be a safe, satisfying, cost effective topical dressing material for decubitus ulcers in general medical and surgical words.

Keywords: antibacterial properties of honey, effect of honey on bedsore, bedsore and honey

\section{INTRODUCTION}

Decubitus ulcer also called as pressure ulcer or bedsore, occur due to pressure applied to soft tissue resulting in completely or partially obstructed blood flow to the soft tissue. They most commonly develop in persons who are non ambulatory and restricted to the bed for most of the time. Certain factors increase the risk of decubitus ulcer development. These factors are protein-calorie malnutrition, micro-climate (skin wetness caused by sweating or incontinence), diseases that reduce blood flow to the skin, such as arteriosclerosis or diseases that reduce the sensation in the skin, such as paresis or neuropathy. These patients already suffer from severe physical distress. Besides, the unsightly appearance and mal odour of the wound the family members are broken psychologically, financially and socially. So management of these ulcers in an economic way is essential. Several materials like povidone iodine solution, metronidazole powder and sucralfate solution are used in day to day practice for dressing of decubitus ulcers.

The medicinal properties of honey have been recognized since ancient time. The antibacterial property of honey was first recognized in 1892 by Van Ketel. Since then honey has been used to treat infections in a wide range of wound types. ${ }^{1}$ Honey is effective in wound healing through improvement of granulation and epithelialisation stages, requirement of debridement and reduction of malodour. ${ }^{1,2}$ Various researchers have shown that honey exerts an antibacterial activity against various organisms, including both Grampositive and Gram-negative bacteria. ${ }^{3}$ The antibacterial 
activity of honey is mainly due to inhibines. These inhibines consist of hydrogen peroxide, flavinoids, and phenolic acids and many other unidentified substances. ${ }^{4}$ A number of reasons for this have been suggested; disruption of the bacterial cell wall due to the osmotic effect of the sugar content, induction of an unfavourable environment with low-water and thereby inhibiting bacterial growth, a low $\mathrm{pH}$ of 3.6 and the fermentation of honey producing alcohol. In situ honey acts as a highly viscous barrier preventing bacterial penetration and colonization of the wound surface. ${ }^{3,4}$ Several studies have shown that, honey can be used as a supplementary material for wound dressing with much shorter time for healing, control of infection, and hospital stay. Recently honey has been proved efficacious in chronic venous ulcerations in lower limb, caesarean section wound and bed sores in cancer patients. Considering all these facts we went ahead with this study as honey is available with ease. ${ }^{1-4}$

\section{MATERIALS AND METHODS}

This is a descriptive, case control study which was single blind and conducted at a tertiary care health centre over a period of one year. Those bed sore patients with size of bed sore $>12,000 \mathrm{cmm}$ and age more than 15 years were included in the study.

Those patients with co-existing illness, who were unable to communicate or who were on concomitant antibiotic therapy were excluded. After carefully considering the inclusion and exclusion criteria a total number of 40 patients were included in the study. Institutional human ethical committee approval was taken prior to the commencement of the study. Informed consents dully signed by the patients were obtained. Patients were randomly grouped into two groups A and $B$ depending on the treatment modality. Twenty patients in the Group A were treated with honey and twenty patients in Group B were treated with povidone iodine. On day 1, we sent pus samples from the wound site for bacteriological identification. Patients from both the groups were treated with other common factors like air bed, timely change in posture and high calorie protein diet. Patients were examined on day 1 and 10 of the treatment to access the status of the bed sore. Status of the bedsore was obtained by both objective and subjective assessment. Objectively we calculated the size of the wound by multiplying the length, breadth and depth. Subjectively the patient was asked to quantify the pain in the Visual analogue scale (VAS) of 0-10; zero meaning no pain and 10 means unbearable pain. On day 10 also pus from the wound site was sent for bacteriological culture to know the reduction in bacterial load.

We considered the null hypothesis of "honey dressing is not superior to conventional Povidone iodine dressing" and proceeded. The relevant parameters were compared using SPSS 21 software. Students t test was used for nominal variables and chi square test was used for categorical variables. Patient characteristics and outcome of interest was calculated with $95 \%$ confidence limits. The probability of $<0.05$ was considered to be significant.

\section{RESULT AND DISCUSSION}

At the onset there was no statistical difference in their demographic profile, duration of the wound, size of the wound and VAS for pain severity (Table-1). At the onset, 8 pus samples were positive for bacteria in Group A, after 48 hours of aerobic incubation. Staphylococcus aureus was most common in 5 samples. Enterococci, Enterobacter and Pseudomonas aeruginosa were isolated in one sample each. In Group-B, 9 pus samples were positive for bacteria at the onset. Staphylococcus aureus was most common in 5 samples followed by Pseudomonas aeruginosa and Enterococci in 2 samples each. On $10^{\text {th }}$ day these parameters were again compared (Table-1). Though the reduction of size of wound was not significant but patients from Group A suffered from less pain than Group B ( $\mathrm{p}=0.010)$. On day 10 , only 2 pus samples were positive for bacteria in Group A and both of them was Stapylococcus aureus and in Group B, only 1 sample was isolated with Enterococci.

The present study shows that the pain was significantly reduced in the honey dressing group at day 10. Though the decrement in size of the wound was more in honey dressing group but

\begin{tabular}{|c|c|c|c|}
\hline Parameter & Group A & Group B & $P$ value \\
\hline Mean age in year $( \pm S D)$ & $60.3 \pm 15.44$ & $59.6 \pm 13.39$ & 0.879 \\
\hline Mean duration of bed sore in days $( \pm S D)$ & $15.05 \pm 0.58$ & $16.45 \pm 0.58$ & 0.288 \\
\hline \multicolumn{4}{|l|}{ Day 1} \\
\hline Mean size of the wound in $\mathrm{cmm}( \pm S D)$ & $32990.80 \pm 13284.29$ & $33840 \pm 12904.28$ & 0.838 \\
\hline Mean visual analogue score $( \pm S D)$ & $6.70 \pm 0.73$ & $6.75 \pm 0.78$ & 0.838 \\
\hline \multicolumn{4}{|l|}{ Day 10} \\
\hline Mean size of the wound in $\mathrm{cmm}( \pm S D)$ & $2592.90 \pm 1276.05$ & $29431 \pm 1660.14$ & 0.459 \\
\hline Mean visual analogue score $( \pm S D)$ & $3.30 \pm 0.47$ & $3.70 \pm 0.47$ & 0.010 \\
\hline
\end{tabular}


the difference was not statistically significant. Looking closely, we could find that there was a large outlier wound in honey dressing group with size of $72896 \mathrm{cmm}$. By cleaning up this outlier and then comparing again, the reduction in size of wound in honey dressing group was significant. The bacterial load in both the groups decreased at day 10 and there was not much difference among both the groups.

Many studies document that honey is cost effective and can provide a better healing which can ultimately provide a sense of well-being and reduce the burden of multiple drug resistant infections. ${ }^{1-4}$ The fact that the antibacterial properties of honey are increased when diluted, was clearly observed and reported in 1919. The explanation for this apparent paradox came from the finding that honey contains an enzyme that produces hydrogen peroxide when diluted. This agent was referred to as 'inhibine' before its identification as hydrogen peroxide. ${ }^{5}$ Hydrogen peroxide is a well-known antimicrobial agent, initially hailed for its antibacterial and cleansing properties. Although the level of hydrogen peroxide in honey is very low, it is still effective as an antimicrobial agent. It has been reported that hydrogen peroxide is more effective when supplied by continuous generation with glucose oxidase than when added in isolation. ${ }^{6,7}$ The harmful effect of hydrogen peroxide is further reduced because honey sequesters and inactivates the free iron, which catalyses the formation of oxygen-free radicals produced by hydrogen peroxide and its antioxidant components help to mop up oxygenfree radicals. ${ }^{8}$ Histologically early attenuation of acute inflammatory changes, control of infection, and early reparative activities were seen with honey treatment. ${ }^{9}$ Molan et al. in a randomised control trial showed 26 patients with postoperative wound infection had their wounds treated with honey and 24 had their wounds washed with $70 \%$ ethanol and povidone iodine applied. The group treated with honey had infection eradicated and achieved complete healing in less than half the time compared with antiseptic treated group. ${ }^{10}$ Similarly, another study done by same author compared 20 consecutive cases of patients with Fournier's gangrene who were treated conservatively with topical application of honey and compared retrospectively with 21 similar cases, managed by orthodox wound debridement methods. Response to treatment and alleviation of morbidity were faster in the honey dressing group. ${ }^{11}$ Development of drug resistance due to indiscriminate use of antibiotics and cost of the treatment involved in these patients are major issues. Oral, parental and topical drugs used to control the infection are highly expensive. Honey used a topical dressing agent is a cost effective alternative.

\section{CONCLUSION}

Honey dressing decreased the pain in bedsore patients significantly. Though the size of the wound was also decreased in honey dressing group but it was not significant in this study. There was also not much difference with bacterial load at the wound site among both the dressing groups. Further study is required with large samples to conclude if honey is better than povidone iodine in bed sore dressing. But to conclude at this point of time honey certainly exerts antibacterial and analgesic properties to the bed sore wound.

\section{REFERENCES}

1. Al-Waili NS and Saloom KY. Effects of topical honey on post-operative wound infections due to gram positive and gram negative bacteria following caesarean sections and hysterectomies. Eur J Med Res 1999; 4:126-130.

2. Topham J. Why do some cavity wounds treated with honey or sugar paste heal without scarring? J Wound Care 2002; 11:53-55.

3. Dunford CE and Hanano R. Acceptability to patients of a honey dressing for non-healing venous leg ulcers. J Wound Care 2004; 13:193-197.

4. Moore OA, Smith LA, Campbell F, Seers K, McQuay HJ and Moore RA. Systematic review of the use of honey as a wound dressing. BMC Complement Altern Med 2001;1:2.

5. Molan PC. The antibacterial effect of honey 1 . The nature of antibacterial activity. Bee World 1992; 73:5-28.

6. In: Turner FJ, editor. Hydrogen Peroxide and other Oxidant Disinfectants. $3^{\text {rd }}$ edn. Philadelphia: Lea and Febiger; 1983.

7. Burdon RH. Superoxide and hydrogen peroxide in relation to mammalian cell proliferation. Free Radic Biol Med 1995; 18:775-794.

8. Koshio $\mathrm{O}$, Akanuma $\mathrm{Y}$ and Kasuga M. Hydrogen peroxide stimulates tyrosine phosphorylation of the insulin receptor and its tyrosinne kinase activity in intact cell. Biochem J 1988; 50:95-101.

9. Tonks A, Cooper RA, Price AJ, Molan PC and Jones KP. Stimulation of TNF-Alpha release in monocytes of honey. Cytokine 2001; 14:240-242.

10. Molan PC and Betts JA. Clinical usage of honey as a wound dressing: An update. J Wound Care 2004; 13:353-356.

11. Molan PC and Russel KM. Non-peroxide antibacterial activity in some New Zealand honeys. J Apic Res 1998;27:62-67.

\section{Authors Contribution:}

SK, DD, TT, RK - conceived and designed the study, analyzed and interpreted the data, searched the literature and made the fi rst draft of the manuscript; HT, SG, PKT - searched the literature and helped the manuscript preparation. All authors reviewed and approved the fi nal manuscript.

Source of Support: Nil, Conflict of Interest: None declared. 